\title{
PENGEMBANGAN BADAN USAHA MILIK DESA (BUMDES) UNTUK KESEJAHTERAAN EKONOMI MASYARAKAT DESA BUKIT RANAH KABUPATEN KAMPAR PROVINSI RIAU
}

\author{
${ }^{1}$ Kiki Joesyiana, ${ }^{2}$ Asepma Hygi Prihastuti, ${ }^{3}$ Sri Wahyuni, ${ }^{4}$ Desi Susanti, ${ }^{5}$ Sri Wahyuni \\ 1,2,3,4 Sekolah Tinggi Ilmu Ekonomi Persada Bunda, Pekanbaru, Riau \\ email : kiki.joesyana@stiepersadabunda.ac.id
}

(Diterima: 12 September 2021; Direvisi: 14 Oktober 2021; Dipublikasikan: November 2021)

\begin{abstract}
Abstrak
Pengabdian ini bertujuan untuk memberikan pengetahuan kepada warga desa bukit ranah khususnya anggota Badan Usaha Milik Desa bukit ranah agar dapat memaksimalkan manfaat dari keberadaan BUMdes yang mereka miliki dan mampu mengelola serta mengembangkan BUMdes tersebut agar dapat membantu memberikan modal usaha awal kepada anggota koperasi yaitu warga desa bukit ranah, Sehingga untuk kedepannya warga desa bukit ranah banyak yang dapat terjun ke dunia bisn is dan bagi yang sudah ada bisnis, dapat memanfaatkan keberadaan BUMdes yang mereka miliki untuk memajukan dan mengembangkan usaha mereka. Badan Usaha Milik Desa merupakan usaha desa yang di kelola oleh pemerintah desa dan berbadan hukum. Pemerintah desa dapat mendirikan badan usaha milik desa seusia dengan kebutuhan dan potensi desa nya msing-masing. Pembentukan badan usaha milik desa di tetapkan dengan peraturan desa. Kepengurusan badan usaha milik desa tediri dari pemerintah desa dan masyarakat setempat. Permodalah badan usaha milik desa dapat berasal dari pemerintah desa, tabungan masyarakat, bantuan pemerintah, pemerintah provinsi dan pemerintah kabupaten/kota, pinjaman, atau penyertaan modal pihak lain atau kerjasama bagi hasil atas dasar saling menguntungkan. Badan usaha milik desa dapat melakukan pinjaman, yang dapat di lakukan setelah mendapat persetujuan BPD. Hingga saat ini sebagian besar bumdes masih sebatas berdiri dan belum memiliki aktifitas usaha yang menghasilkan di karenakan beragam masalah yang membuatBUMdes belum tumbuh sesuai harapan. Di Desa Bukit Ranah terdapat Badan Usaha Milik Desa yang berbadan hukum yang mana anggotanyaa adalah warga desa bukit ranah itu sendiri.
\end{abstract}

Kata Kunci: Pengembangan, Badan Usaha Milik Desa, Kesejahteraan Ekonomi

Abstract:
This service aims to provide knowledge to the residents of the hill realm village, especially members of the Bukit realm Village Owned Enterprise so that they can maximize the benefits of the existence of the BUMdes that they have and are able to manage and develop the BUMdes in order to help provide initial business capital to cooperative members, namely the residents of the hill village. realm, so that in the future many hill village residents can enter the business world and for those who already have a business, can take advantage of the existence of BUMdes that they have to advance and develop their business. Village-Owned Enterprises are village businesses that are managed by the village government and are legal entities. The village government can establish village-owned enterprises of the same age as the needs and potentials of each village. The formation of village-owned enterprises is determined by village regulations. The management of village-owned enterprises consists of the village government and the local community. The capital of village-owned enterprises can come from the village government, community savings, government assistance, provincial governments and district/city governments, loans, or other party's capital participation or profit-sharing cooperation on the basis of mutual benefit. Villageowned enterprises can make loans, which can be done after obtaining BPD approval. Until now, most BUMDes are still standing and do not have productive business activities due to various problems that have prevented BUMdes from growing as expected. In Bukit Ranah Village there is a Village-Owned Business Entity which is a legal entity whose members are residents of the hill realm village itself.

Keywords: Development, Village-Owned Enterprises, Economic Welfare 


\section{PENDAHULUAN}

Pemenuhan kesejahteraan umum dan ekonomi desa harus menjadi tulang punggung yang di bangun dengan kokoh. Pembangunan ketahanan ekonomi desa membutuhkan kesadaran dan upaya bersama semua komponen termasuk di setiap tingkat makro, mikro, bahkan pada setiap tingkat yang dapat secara unik didefinisikan. Bukan saja ketahanan ekonomi namun juga bagaimana pembangunan juga mampu mendefinisikan kesejahteraan adaptif desa sebagai kesejahteraan yang sesuai dengan kearifan lokal desa tersebut. Kesejahteraan yang bukan 'meniru atau mengikuti' parameter desa atau tempat lain. Kesejahteraan yang 'menyesuaikan' dengan apa yang diberikan oleh Tuhan berupa alam dan hasil bumi serta keunikkan masyarakatnya.

Tabel 1

Indeks Pembangunan Manusia Kabupaten Kampar

\begin{tabular}{|c|c|}
\hline TAHUN & JUMLAH PERSENTASE IPM \\
\hline 2018 & 72,50 \\
\hline 2019 & 73,15 \\
\hline 2020 & 72,83 \\
\hline
\end{tabular}

Sumber : Badan Pusat Statistik Provinsi Riau

Pengelolaan BUMDes dilakukan oleh Pemerintah Desa bersama dengan masyarakat. BUMDes menjadi bagian lembaga yang dapat menopang kesejahteran warga desa, dan tentunya harapan tersebut dapat diiringi dengan meningkatnya Indeks Pembangunan Manusia (IPM). Dilihat dari table 1, terlihat bahwa tidak ada peningkatan terhadap IPM kabupaten Kampar dari tahun 2018-2020. Bahkan di tahun 2020 terdapat penurunan persentase IPM. Hal ini merupakan salah satu dasar pemilihan dilaksanakannya Pengabdian ini.

Berbagai potensi desa ada di Kabupaten Kampar mulai dari keindahan alam hingga keunikan budaya dan masyarakatnya. Potensi sumber daya manusia yang tersimpan di salah satu desa di Kabupaten Kampar adalah Desa Bukit Ranah. Desa Bukit Ranah memiliki potensi sumber daya manusia dan organisasi kemasyarakatan yang menggerakkan dinamika sosiokultural di Desa Bukit Ranah. PKK (Pendidikan Kesejahteraan Keluarga), Gapoktan (Gabungan Kelompok Tani), Karang Taruna merupakan tiga organisasi kemasyarakatan yang terlibat secara aktif dan partisipatif dalam perencanaan pembangunan desa. Masyarakat mulai sadar jika kelompok perempuan yang mayoritas tergabung dalam PKK Desa memiliki semangat untuk dapat aktif terlibat secara langsung dalam perencanaan dan pengambilan kebijakan di desa.

Tidak hanya kelompok perempuan yang menunjukkan geliatnya, tetapi sebagian generasi muda Desa Bukit Ranah telah menyadari kebutuhan regenerasi petani. Namun demikian, potensi sumber daya manusia di Desa Bukit Ranah tersebut belum sepenuhnya optimal untuk kemanfaatan bersama dengan BUMDes. Mengkaji potensi fisik dan non-fisik di Desa Bukit Ranah, nampak jika masyarakat setempat memiliki dorongan untuk mencari jawaban dan menyelesaikan kompleksitas berbagai permasalahan bersama. Terdapat beberapa masalah yang dihadapi warga Desa Bukit Ranah yaitu (1) perlunya sosialisasi lebih mengenai BUMDes dan produknya bagi masyarakat; (2) belum ditemukannya karakter khusus atau keunikan desa; (3) kurangnya motivasi masyarakat, dikarenakan kecenderungan pengembangan desa lebih kearah infrasruktur; dan (4) pemuda kurang aktif dikarenakan terpisah pisahnya padukuhan dan belum dilibatkan dalam pemasaran produk BUMDes. 
Merujuk pada kualitas produk BUMDes yang belum sepenuhnya terkontrol dan masyarakat-masyarakat desa juga belum sepenuhnya mengerti manfaat BUMDes maka diperlukan penyuluhan yang bertujuan untuk dapat mengembangkan kualitas usaha milik desa dan melestarikan ketahanan ekonomi masyarakat dengan sistem kewirausahaan yang lebih baik. Pengabdian ini akan menjelaskan secara sistematis tentang penumbuhan kolaborasi antara desa dan wirausahawan melalui BUMDes dalam Q-BUMDes dengan menggunakan Model Tetrapreneur (Fatimah, 2018). Desa Ranah adalah salah satu Desa pemekaran dari Desa Airtiris yang terletak di Kecamatan Kampar Kabupaten Kampar sekitar 50 km dari ibu kota Provinsi Riau. Menurut data statistik di kantor kepala Desa Ranah, Desa Ranah memiliki luas wilayah $2585 \mathrm{Ha}$, yang terdiri dari lahan pertanian, perkebunan, pemukiman, dan pekarangan. Desa Ranah terdiri dari 4 Dusun, 16 RW dan 16 RT. Keadaan iklim Desa Ranah tidak jauh berbeda dengan daerah lainnya yaitu tidak terlalu panas dan tidak terlalu dingin ini karena Desa Ranah mempunyai pepohonan seperti pohon kelapa, rambutan, pohon pinang dan lainnya. Desa Ranah telah mengelola: simpan pinjam di BUMDes yang mereka kelola.

BUMDes Desa Ranah menjadi bagian lembaga yang dapat menopang kesejahteran warga desa, dan tentunya harapan tersebut dapat diiringi dengan adanya penyuluhan ini yang membahas usaha desa di Desa Ranah yang memiliki banyak produk masyarakat tetapi existensinya belum maksimal. Masyarakat Desa ranah berharap setiap desa mempunyai pariwisata melalui perkebunan dan sungai yang ada di dalam desa ranah. Secara teknologi produksi bagus, dari segi rasa bagus, namun tidak bertahan karena tidak dapat memasarkan. Contoh produk olahan singkong dan hasil kebun sudah bagus dari segi rasa dan hasil, namun belum dapat memasarkan. Selain masalah dalam pemasaran, kurangnya desain kemasan juga mengurangi mutu produk. Ini semua karena kurangnya perhatian dan focus para aparat desa dan masyarakat desa ranah dalam memanfaatkan peluang dari adanya BUMDes.

Peran dan partisipasi masyarakat sangatlah dibutuhkan demi kelancaran pembangunan. Sumber daya manusia merupakan suatu faktor produksi yang penting karena produktifitas sumber daya manusia akan mempengaruhi faktor-faktor produksi yang lain seperti sumber daya alam, pembentukan modal, teknologi, dan kewirausahaan. Peningkatan produktifitas, sumber daya manusia dan sumber daya alam yang jumlahnya sangat terbatas dapat diolah oleh manusia dengan berbagai keahlian yang dimiliki, didukung oleh teknologi dan kewirausahaan untuk memenuhi tuntutan pembangunan dalam rangka peningkatan kesejahteraan masyarakat.

Warga Desa Bukit Ranah Kabupaten Kampar Provinsi Riau mayoritas memiliki usaha perkebunan, yaitu kebun sawit, durian, jeruk dan singkong. Desa Bukit Ranah juga memiliki koperasi yang dimana anggota koperasinya belum memanfaatkan secara maksimal keberadaan koperasi tersebut untuk membangun usaha/bisnis mereka. Kendala warga Desa Bukit Ranah Kabupaten Kampar dalam usaha awal membuka bisnis adalah di modal.

\section{METODE}

Metode yang digunakan dalam kegiatan pengabdian ini adalah metode ceramah, yaitu suatu metode penyampaian dengan menggunakan komunikasi lisan. Agar metode ceramah berhasil, menurut (Sanjaya, 2019) ada beberapa hal yang harus dilakukan, yaitu:

1. Tahap persiapan

Mencakup didalamnya merumuskan tujuan yang ingin dicapai, menentukan pokok-pokok materi yang ingin diceramahkan, dan mempersiapkan alat bantu. 
2. Tahap pelaksanaan

Langkah pembukaan, langkah penyajian, langkah mengakhiri atau penutup ceramah.

Metode yang akan dilakukan oleh tim selama kegiatan pengabdian bagi kepada kelompok warga Desa Bukit Ranah Kabupaten Kampar Provins Riau adalah sebagai berikut:

1. Pemberian materi tentang strategi meningkatkan kualitas BUMDes Pada kegiatan ini akan dilakukan pemberian motivasi pentingnya meningkatkan kualitas BUMDes. Kegiatan ini dilakukan dalam bentuk pelatihan motivasi jiwa untuk lebih mengembangkan pemahaman yang telah dimiliki warga desa Bukit Ranah. Kegiatan ini dilakukan dalam bentuk tukar pengalaman dengan pemateri dari desa yang BUMDes nya sudah sukses.

2. Pemberian materi tentang strategi dalam meningkatkan kesejahteraan ekonomi warga Desa Bukit Ranah. Kegiatan ini dilakukan dengan memberikan materi tentang strategi dalam meningkatkan kesejahteraan masyarakat dengan pemanfaatan BUMDes yang desa Bukit Ranah miliki.

3. Pengenalan kepada lembaga pemerintahan yang dapat memberikan informasi penyaluran dana bantuan bagi masing-masing BUMDes seluruh Indonesia dari pemerintah pusat.

\section{Gambar 1 Anggota Badan Usaha Milik Desa Bukit Ranah}

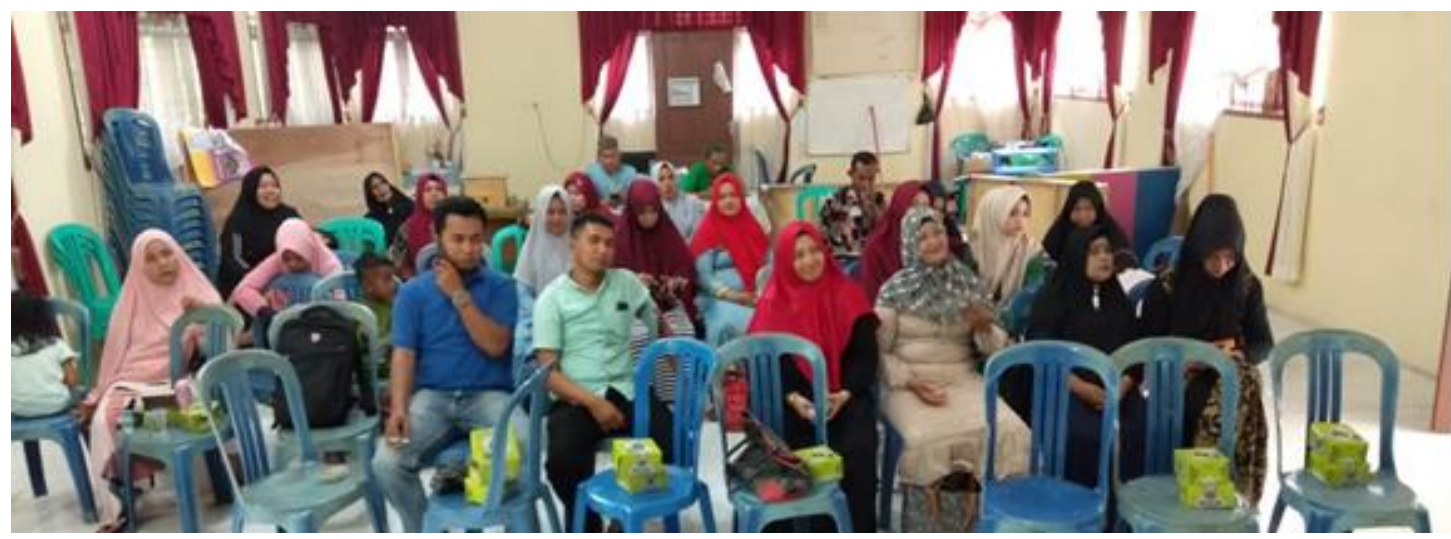

Sumber : Kantor Kepala Desa Bukit Ranah

\section{HASIL dan PEMBAHASAN}

BUMDes di Desa Bukit Ranah sudah berdiri kurang lebih 2 tahun. Sumber modalnya berasal dari anggaran Dana Desa, dimana besarnya modal yang diberikan di tahun 2019 sebesar Rp. 50.000.000, dan ditahun 2020 sebesar Rp. 60.000.000. Di tahun pertama, unit usah a yang dibentuk adalah unit simpan pinjam tetapi dalam kegiatannya banyak mengalami kendala, khususnya masalah kredit macet. Hal ini disebabkan karena masih rendahnya tanggung jawab nasabah dalam mengembalikan pinjaman, juga dikarenakan pekerjaan nasabah di Desa Bukit Ranah yang rata-rata bekerja sebagai petani dan pedagang, dimana penghasilannya mengalami pasang surut serta belum adanya legalitas mengenai penarikan agunan jika ada nasabah yang menunggak, saat ini yang sudah dilakukan adalah pengelola BUMDes adalah dengan menagih dari rumah ke rumah (masih dengan suasana kekeluargaan). Dikarenakan adanya kendala 
kredit macet ini sehingga modal usaha yang ada tidak dapat diputar kembali dan unit usaha simpan pinjam tidak berkembang.

\section{Gambar 2 \\ Skema Permodalan Bumdes}

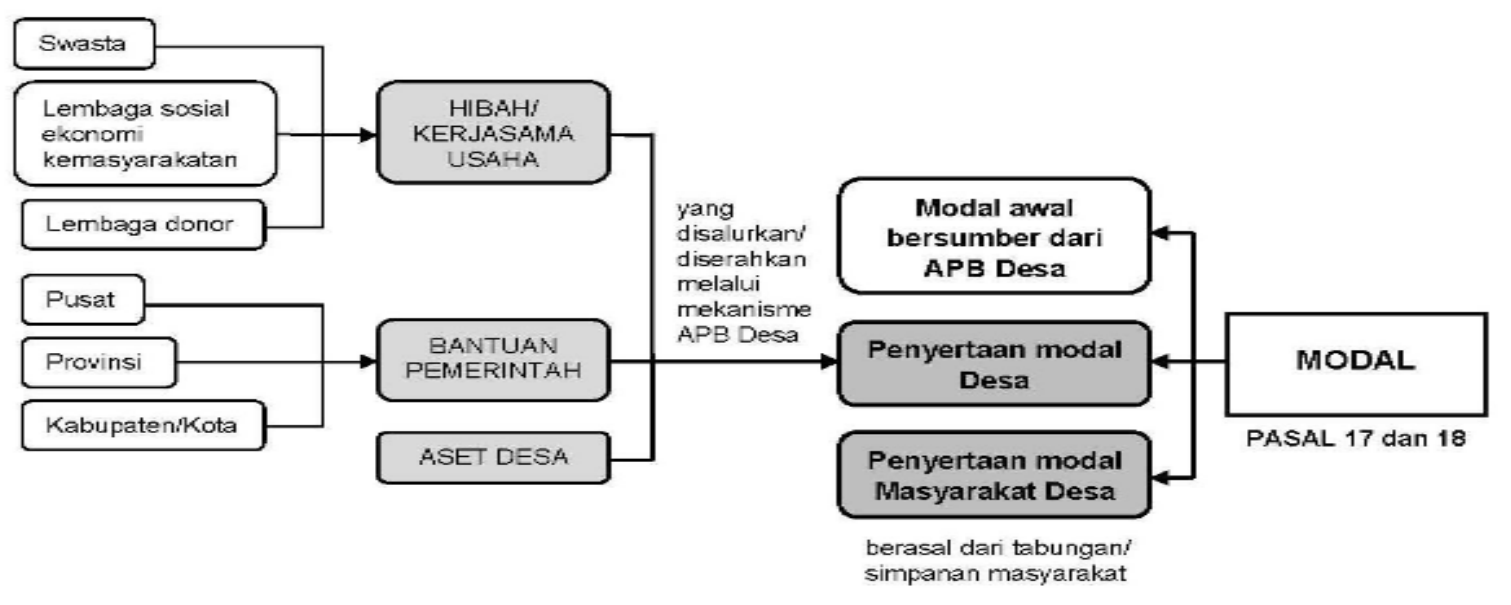

\section{Sumber : Kantor Kepala Desa Bukit Ranah Kabupaten Kampar}

Berdasarkan pengalaman di tahun sebelumnya, maka pengelola BUMDes membentuk usaha unit baru yaitu beternak ikan patin, saat ini unit usaha ini sudah berjalan 3 bulan dan belum panen, kendala utama pada kurangnya modal untuk menambah jumlah bibit ikan patin. Direncanakan akan dibuat 8 kolam saat ini baru tersedia 1 kolam, agar panen dapat dilakukan setiap hari dan dapat dijual keluar daerah Desa Bukit Ranah.

Kemudian adanya kesulitan BUMDes dalam merekrut pengurus BUMDes karena masih minimnya masyarakat yang berminat menjadi pengelola/pengurus BUMDes, dikarenakan belum adanya kejelasan gaji tetap, hal ini juga merupakan salah satu yang menyebabkan unit usaha belum berjalan secara maksimal.

Dengan adanya permasalahan yang ada sehingga menghambat berkembanganya BUMDes di Desa Bukit Ranah ini, maka diadakanlah kegiatan Pengabdian Kepada Masyarakat dalam rangka meningkatkan kualitas BUMDes-nya dan untuk membuka pikiran dan pandangan masyarakat Desa Bukit Ranah serta perangkat desanya tentang pentingnya peran BUMDes bagi kesejahteraan warga Desa Bukit Ranah sendiri.

Pada dasarnya BUMDes memiliki peran sebagai pilar Demokrasi Ekonomi yang memfokuskan pada kemandirian suatu daerah dalam mengelola asset daerah demi kesejahteraan masyarakatnya. Mengapa BUMDes memiliki peran sebagai pilar Demokrasi Ekonomi, karena:

1. BUMDes sebagai lembaga ekonomi masyarakat yang berperan strategis untuk menggairahkan ekonomi desa.

2. Keunikan BUMDes yakni merupakan sebuah usaha desa milik kolektif yang digerakkan oleh aksi kolektif antara pemerintah desa dan masyarakat (Public and Community Partnership).

3. BUMDes dibentuk atas dasar komitmen bersama masyarakat desa untuk saling bekerja sama dan menggalang kekuatan ekonomi rakyat demi mewujudkan kesejahteraan dan kemakmuran masyarakat desa. Pengembangan dan pembentukan BUMDes merupakan 
prospek menjanjikan untuk menguatkan dan memberdayakan lembaga-lembaga ekonomi desa. Sehingga BUMDes memiliki nilai transformasi sosial, ekonomi dan budaya. Hal inilah yang menjadikan BUMDes sebagai salah satu lembaga ekonomi rakyat yang berperan sebagai PILAR DEMOKRASI EKONOMI.

Beberapa hal yang harus segera dilakukan dalam rangka penataan perekonomian desa melalui BUMDes:

a. Memperkuat kapasitas masyarakat untuk turut mengawasi berjalannya usaha dari BUMDes.

b. Strukturorganisasi BUMDes yang menunjukan peranan kuat dan peran pemerintah desa harus dikurangi namun tetap memperhatikan penasihat dijabat secara Ex-officio oleh Kades

c. Kegiatan ekonomi harus mengakar dengan kondisi sosial masyarakat desa

d. Kegiatan ekonomi sesuai dengan potensi dan aset yang dimiliki desa.

e. Pendistribusian manfaat BUMDes harus dilakukan secara adil, jelas dan transparan dan modern

Setelah dilakukan kegiatan Pengabdian Kepada Masyarakat ini, pengelola BUMDes di Desa Bukit Ranah mengambil beberapa solusi untuk masalah yang sekarang sedang dihadapinya, seperti:

1) Untuk unit usaha simpan pinjam akan dihentikan dulu kegiatan pemberian pinjamannya, dan akan focus pada pengembalian modal pinjaman yang telah dilakukan oleh nasabah.

2) Kegiatan usaha akan difokuskan pada unit usaha ternak ikan patin dan modal yang diterima dari Dana Desa akan digunakan untuk pembelian bibit ikan patin dan pembuatan kolam. Bersama hal itu juga mulai mencari pangsa pasar dalam menjual hasil ikan patin yang dipanen untuk dijual keluar Kabupaten Kampar. Serta akan dikembangkan hasil olahan ikan patin yang dihasilkan, seperti: kerupuk ikan patin, salai ikan patin, dll.

3) Untuk menambah penghasilan unit usaha ternak ikan patin, BUMDes juga akan membuat pakan ikan sendiri dengan rencana akan membeli peralatan pengolahan pakan ikan, yang mana nanti hasilnya dapat digunakan untuk usaha sendiri ataupun dijual keluar desa.

4) BUMDes kedepannya juga ingin membuka unit usaha baru seperti Wisata Hutan Bakau yang mana belum ada di Kabupaten Kampar, hal ini sangat baik bagi daerah sekitar karena sebagian besar wilayah Kampar adalah rawa dan hutan bakau sangat berperan dalam mengurangi abrasi di sekitar Daerah Aliran Sungai Kampar. Dimana saat ini ketika curah hujan lebat, daerah Desa Bukit Ranah terkena banjir.

5) Dalam hal pemasaran, BUMDes akan berusaha untuk:s

- Membangun pusat pemasaran khusus dan outlet untuk produk BUMDes;

- Menyusun/menegakkan regulasi yang mewajibkan pasar modern (Giant, Indomaret, Alfamart, dll.) untuk ikut memasarkan produk-produk BUMDes;

- Menerapkan linkage strategy antara BUMDes penghasil bahan baku perantara dengan industri yang bergerak di sektor hilir (termasuk dengan BUMN). Dalam skema ini, BUMDes berfungsi sebagai penyedia input bagi industri pengolahan akhir. 


\section{Gambar 3 \\ Foto Bersama Pemateri dan Anggota BUMDES Bukit Ranah}

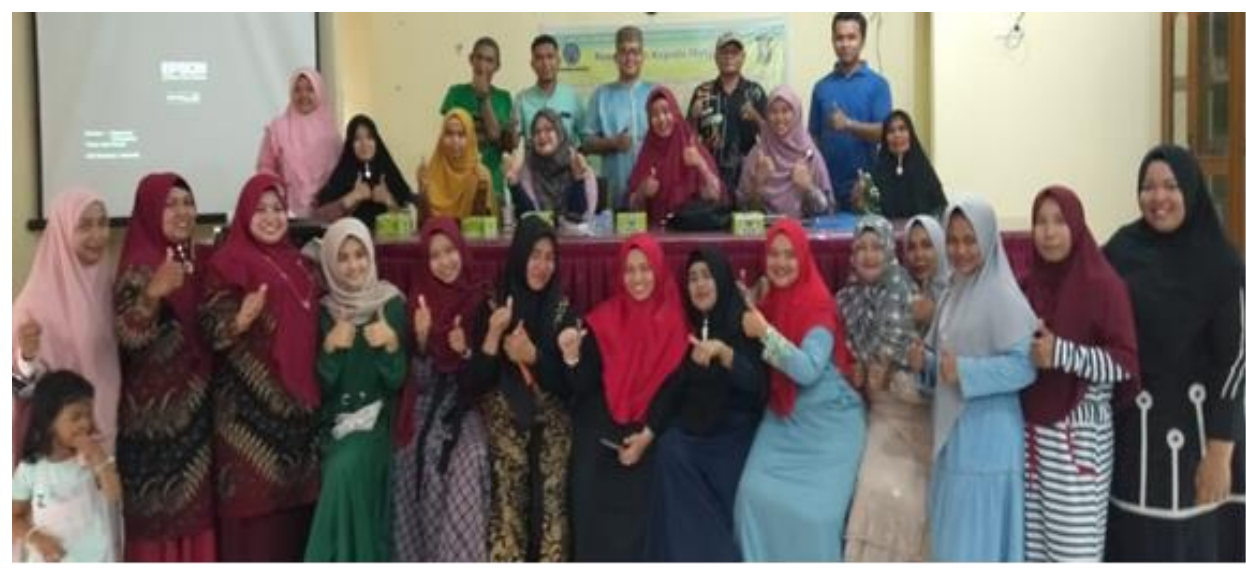

\section{Sumber : Kantor Kepala Desa Bukit Ranah}

\section{SIMPULAN}

Setelah melakukan kegiatan Pengabdian Kepada Masyarakat pada Badan Usaha Milik Desa (BUMDES) Desa Bukit Ranah Kabupaten Kampar, dapat ditarik kesimpulan bahwa:

1. Peran BUMDes di Desa Bukit Ranah belum maksimal karena baru berdiri 2 tahun dan unit usaha yang dimiliki yaitu unit usaha simpan pinjam dan beternak ikan patin. Untuk usaha unit simpan pinjam banyak mengalami kendala, khususnya masalah kredit macet, sehingga modal usaha yang ada tidak dapat diputar kembali. Hal ini disebabkan karena belum adanya legalitas mengenai penarikan agunan jika ada nasabah yang menunggak, saat ini yang sudah dilakukan adalah pengelola BUMDes menagih dari rumah ke rumah (masih dengan suasana kekluargaan). Sedangkan untuk unit usaha beternak ikan patin saat ini sudah berjalan 3 bulan dan belum panen, kendala utama pada kurangnya modal untuk menambah jumlah bibit ikan patin. Direncanakan akan dibuat 8 kolam saat ini baru tersedia 1 kolam, agar panen dapat dilakukan setiap hari dan dapat dijual keluar daerah Desa Bukit Ranah.

2. Kesulitan BUMDes dalam merekrut pengurus BUMDes karena masih minimnya masyarakat yang berminat menjadi pengelola/pengurus BUMDes, dikarenakan belum adanya kejelasan gaji tetap, hal ini juga merupakan salah satu yang menyebabkan unit usaha belum berjalan secara maksimal.

3. BUMDES di Desa Bukit Ranah kedepannya ingin membuka unit usaha baru seperti Wisata Hutan Bakau yang mana belum ada di Kabupaten Kampar, hal ini sangat baik bagi daerah sekitar karena sebagian besar wilayah Kampar adalah rawa dan hutan bakau sangat berperan dalam mengurangi abrasi di sekitar Daerah Aliran Sungai Kampar. Dimana saat ini ketika curah hujan lebat, daerah Desa Bukit Ranah terkena banjir.

\section{SARAN}

Dengan telah dilakukannya Pengabdian Kepada Masyarakat pada BUMDes di Desa Bukit Ranah kedepannya diharapkan:

1. BUMDes di Desa Bukit Ranah dapat dikelola secara profesional dan mengedepankan nilai-nilai dan prinsip sesuai dengan kebutuhan dan kondisi perekonomian masyarakat 
desa dengan membuat unit usaha baru sehingga dapat meningkatkan Pendapatan Asli Desa (PADes) dan mensejahterakan masyarakat di Desa tersebut.

2. Bagi pemerintah desa diharapkan dapat memberikan fasilitas yang diperlukan terutama untuk anggaran gaji pengelola BUMDes, serta meningkatkan anggaran dari Dana Desa untuk pengembangan unit usaha BUMDes.

3. Para akademisi diharapkan lebih aktif untuk memberikan dukungan pemikiran dan solusi yang diperlukan untuk mengembangakan potensi yang ada di desa.

\section{UCAPAN TERIMA KASIH}

Segala puji dan syukur kami panjatkan ke hadirat Allah SWT yang telah memberikan kesempatan kepada kami Tim PkM Dosen Sekolah Tinggi Ilmu Ekonomi Persada Bunda Pekanbaru untuk melaksanakan Pengabdian Kepada Masyarakat (PKM) sebagai salah satu perwujudan dan pelaksanaan dari Tridharma Perguruan Tinggi. Ucapan terimakasih kepada Kepala Desa Bukit Ranah, Ketua Badan Usaha Milik Desa Bukit Ranah dan seluruh Anggota Badan Usaha Milik Desa Bukit Ranah atas bantuan dan partisipasinya atas kegiatan ini. Dan terimakasih juga kepada Ketua STIE Persada Bunda serta Yayasan Pendidikan Persada Bunda atas Dukungan baik secara Moril dan Materil kepada Tim Kami.

\section{REFERENSI}

Chikmawati, Zulifah. "Peran Bumdes Dalam Meningkatkan Pertumbuhan Ekonomi Pedesaan Melalui Penguatan Sumber Daya Manusia." Jurnal Hukum Islam, 2019, 13.

Dewi, Amelia Sri Kusuma. "PERANAN BADAN USAHA MILIK DESA (BUMDes) SEBAGAI UPAYADALAM MENINGKATKAN PENDAPATAN ASLI DESA (PADes) SERTA MENUMBUHKAN PEREKONOMIAN DESA," no. 1 (2014): 14

Herry Kamaroesid, Tata Cara Pendirian dan Pengelolaan BUMDES, (Jakarta: Mitra Wacana media)

Hunger, D. dan Thomas W. 2014. Manajemen Strategis. Yogyakarta: Andi

Kementerian Desa, Pembangunan Daerah Tertinggal dan Transmigrasi.2017. Buku Pegangan Pengelolaan Bumdes.Jakarta

Muhammad, S. 2017. Manajemen Strategik: Konsep dan Alat Analisis.Yogyakarta: UPP STIM YKPN

Osterwalder, Alexander and Yves Pigneur.2010. Business Model Generation. Hoboken, New Jersey: John Wiley \& Sons, Inc.

Permendesa PDTT No. 4 Tahun 2015 tentang Pendirian, Pengurusan dan Pengelolaan, dan Pembubaran Badan Usaha Milik Desa.

Pemerintah republik indonesia. "peraturan pemerintah republik indonesia nomor 47 tahun 2015 tentang perubahan atas peraturan pemerintah nomor 43 tahun 2014 tentang peraturan pelaksanaan undang-undang nomor 6 tahun 2014 tentang desa,"

n.d._-_ "undang-undang republik indonesia nomor 6 tahun 2014 tentang desa," n.d.

Soleh, Ahmad. "STRATEGI PENGEMBANGAN POTENSI DESA," 2017, 21

Fatimah, P. L. R. (2018). Mengembangkan Kualitas Usaha Milik Desa (Q-BUMDes) untuk Melestarikan Ketahanan Ekonomi Masyarakat dan Kesejahteraan Adaptif: Perancangan Sistem Kewirausahaan Desa dengan Menggunakan Model Tetrapreneur. Jurnal Studi Pemuda, $7(2), 122-132$.

Sanjaya, W. (2019). Strategi pembelajaran berorientasi standar proses pendidikan. 